\title{
Robustness of biomarker determination in breast cancer by RT-qPCR: impact of tumor cell content, DCIS and non-neoplastic breast tissue
}

Kerstin Hartmann ${ }^{1 * \dagger}$, Kornelia Schlombs ${ }^{1+}$, Mark Laible ${ }^{1}$, Claudia Gürtler ${ }^{1}$, Marcus Schmidt ${ }^{2}$, Ugur Sahin $^{3}$ and Hans-Anton Lehr ${ }^{4}$

\begin{abstract}
Background: Tissue heterogeneity in formalin-fixed paraffin-embedded (FFPE) breast cancer specimens may affect the accuracy of reverse transcription quantitative real-time PCR (RT-qPCR). Herein, we tested the impact of tissue heterogeneity of breast cancer specimen on the RT-qPCR-based gene expression assay MammaTyper ${ }^{\oplus}$.

Methods: MammaTyper ${ }^{\oplus}$ quantifies the mRNA expression of the four biomarkers ERBB2, ESR1, PGR, and MKI67. Based on pre-defined cut-off values, this molecular in vitro diagnostic assay permits binary marker classification and determination of breast cancer subtypes as defined by St Gallen 2013. In this study, we compared data from whole FFPE sections with data obtained in paired RNA samples after enrichment for invasive carcinoma via macro- or laser-capture micro-dissection.

Results: Compared to whole sections, removal of surrounding adipose tissue by macrodissection generated mean absolute 40 -ddCq differences of $0.28-0.32$ cycles for all four markers, with $\geq 90 \%$ concordant binary classifications. The mean raw marker $\mathrm{Cq}$ values in the adipose tissue were delayed by 6 to 7 cycles compared with the tumorenriched sections, adding a trivial linear fold change of 1.0078 to 1.0156 . Comparison of specimens enriched for invasive tumor with whole sections with as few as $20 \%$ tumor cell content resulted in mean absolute differences that remained on average below $0.59 \mathrm{Cq}$. The mean absolute difference between whole sections containing up to $60 \%$ ductal carcinoma in situ (DCIS) and specimens after dissection of DCIS was only $0.16-0.25$ cycles, although there was a tendency for higher gene expression in DCIS. Observed variations were related to small size of samples and proximity of values to the limit of detection.
\end{abstract}

Conclusion: Expression of ESR1, PGR, ERBB2 and MKI67 by MammaTyper ${ }^{\circledR}$ is robust in clinical FFPE samples. Assay performance was unaffected by adipose tissue and was stable in samples with as few as $20 \%$ tumor cell content and up to $60 \%$ DCIS.

Keywords: Breast cancer, MammaTyper, RT-qPCR, DCIS, Tumor cell content, Non-neoplastic tissue, Tissue heterogeneity

\footnotetext{
* Correspondence: kerstin.hartmann@biontech.de

${ }^{\dagger}$ Kerstin Hartmann and Kornelia Schlombs contributed equally to this work.

${ }^{1}$ BioNTech Diagnostics GmbH, An der Goldgrube 12, 55131 Mainz, Germany

Full list of author information is available at the end of the article
}

(c) The Author(s). 2018 Open Access This article is distributed under the terms of the Creative Commons Attribution 4.0 International License (http://creativecommons.org/licenses/by/4.0/), which permits unrestricted use, distribution, and reproduction in any medium, provided you give appropriate credit to the original author(s) and the source, provide a link to the Creative Commons license, and indicate if changes were made. The Creative Commons Public Domain Dedication waiver (http://creativecommons.org/publicdomain/zero/1.0/) applies to the data made available in this article, unless otherwise stated. 


\section{Background}

Heterogeneity is an intrinsic property of formalin-fixed paraffin-embedded (FFPE) tumor material from core needle biopsies or resection specimens of breast carcinomas. On hematoxylin and eosin (H\&E) stained histological slides, invasive tumor cells are seen in close proximity to other neoplastic or non-neoplastic microanatomical structures such as in situ carcinoma, atypical ductal hyperplasia, non-neoplastic ductulo-lobular structures, and stromal cells, including adipocytes, blood vessels, and other cells of the tumor microenvironment. These morphologically distinct cell types have unique biological and molecular fingerprints [1-4].

During the diagnostic work-up of breast carcinomas, immunohistochemistry (IHC) is the standard method for assessing the expression of estrogen- (ER) and progesterone-receptors (PR), human epidermal growth factor receptor 2 (HER2) as well as of Ki-67 as a marker of tumor cell proliferation. Biomarker studies are routinely performed in order to classify breast carcinomas into prognostic and therapeutic categories [5]. The fact that tissue morphology is preserved on IHC-stained slides makes it possible to assess biomarker expression specifically in the invasive tumor compartment, regardless of heterogeneity. However, IHC requires interpretation of the chromogen signal and semi-quantitative scoring of intensity or proportion of staining, procedures that are both subject to intra- and inter-observer variability and will hence result in discordance rates [6-9].

Quantification of gene expression by reverse transcription-quantitative real-time PCR (RT-qPCR) precludes such subjective interpretation. However, contrary to IHC, RT-qPCR uses RNA extracted from FFPE sections, containing both invasive tumor as well as non-tumorous cells of the tumor microenvironment. Therefore, gene expression data may thus be affected by the presence of heterogeneous cell types whose expression patterns can differ substantially from the invasive tumor $[3,4,10,11]$. With the advent of molecular subtyping of breast cancer and the clinical endorsement of RNA-based genomic risk scores tissue heterogeneity has to be considered a potential confounder and is usually addressed by assay-specific requirements for "minimum tumor content" [12]. Macrodissection or the more time-consuming microdissection is usually applied to increase tumor cell content (TCC) in the diagnostic setting.

The MammaTyper is an RT-qPCR-based, CE-marked molecular in vitro diagnostic assay used for categorizing tumor resection specimens and pre-operative core needle biopsies of breast carcinomas into five subtypes (luminal A-like, luminal B-like (HER2-positive), luminal B-like (HER2-negative), HER2-positive (non-luminal) and triple negative (ductal)) as defined by the $2013 \mathrm{St}$ Gallen consensus [13]. The assay quantifies the mRNA expression of four genes ERBB2 (HER2), ESR1 (ER), $P G R$ (PR) and MKI67 (marker of proliferation Ki-67) relative to the mean expression of two reference genes and generates a dichotomous result (positive or negative) based on predefined cut-off values [14].

MammaTyper may evolve as a valid alternative to IHC. This is supported by the substantial correlation that exists between protein and mRNA expression in general [15] and for breast cancer biomarkers in particular [16-18] and by the desire to increase the reproducibility of biomarker testing, in particular for the assessment of proliferative activity (i.e.Ki-67) [19]. MammaTyper ${ }^{\bullet}$ has shown excellent analytical performance, promising clinical validity both in the adjuvant and neoadjuvant setting, with concordance to IHC documented in more than 800 clinical samples [20-22].

During the assay's technical validation, we have previously studied the robustness of the gene expression assay in the face of tissue heterogeneity [14]. In the present work, we aimed to further examine the impact of tissue heterogeneity on MammaTyper gene expression by investigating "contamination" at both ends of the histological spectrum. It is commonly assumed that non-neoplastic RNA may solely "dilute" the RT-qPCR signal, whereas in situ carcinoma (i.e.DCIS) may affect results in more complex ways due to its unique transcriptional profiles that differ from that of the invasive tumor $[4,23]$. We therefore designed 3 independent experiments to assess the impact of non-neoplastic surrounding tissue on gene expression, in particular adipose tissue and DCIS as well as variations in TCC.

\section{Methods}

\section{Sample selection and tissue handling}

The study consisted of 49 FFPE resection specimens of invasive breast carcinoma. Thirteen cases were from the Institute of Molecular Gynecological Oncology, Mainz, Germany. The use of archived samples was approved by the ethics committee of the Landesärztekammer Rheinland-Pfalz (837.139.05 (4797)). Thirty one cases were obtained from PATH Biobank (Patients' Tumour Bank of Hope), Munich, Germany [24]. Patients provided individual, written informed consent for the storage of samples and data, follow-up contact, and further use of samples and data for research purposes. The processes of PATH Biobank have been approved by the ethics committee of the medical faculty of the University of Bonn (255/06). Five additional cases were purchased from commercial vendors (Asterand Biosciences, Detroit, USA MI; Proteogenex, Culver City, USA CA).

Histological review was performed on H\&E slides by an experienced pathologist who identified and evaluated the percentage of the various tissue components (non-neoplastic tissue, invasive tumor and DCIS). The effect 
of adipose tissue, tumor cell content (TCC) and DCIS on the results of MammaTyper ${ }^{\circ}$ for each individual breast cancer marker was investigated in different experiments (Fig. 1). TCC was defined as the planimetric ratio of areas covered by invasive carcinoma in relation to the area covered by DCIS and by non-neoplastic tissue (including connective and necrotic tissue). Because of its paucicellular nature, scar and adipose tissue were not considered as non-neoplastic tissue. The size of the tumor area $\left(\mathrm{mm}^{2}\right)$ was calculated using the ZEN2 (blue edition) software from Carl Zeiss Microscopy GmbH 2011.

To study the effect of adipose tissue on gene expression, we selected 10 FFPE samples with surrounding adipose tissue which accounted for at least 50\% of the whole section. To exclude effects of other tissue components such as non-neoplastic tissue, only samples with 80 to $100 \%$ tumor cell content were used. Furthermore, in order to minimize effects of DCIS on assay results, only samples with less than $10 \%$ DCIS content were selected for these experiments (8 samples: 0\% DCIS; 2 samples: $\leq 10 \%$ DCIS). In addition to a $10 \mu \mathrm{m}$ curl representing the whole section, three consecutive $5 \mu \mathrm{m}$ sections were mounted on glass slides and the invasive tumor area of each slide as well as the adipose tissue were macrodissected and transferred into separate RNase-free tubes for subsequent RNA isolation (Fig. 1, upper panel). Relative expression of the four genes ERBB2, ESR1, PGR and MKI67 in the whole sections was compared with relative gene expression in the dissected invasive tumor and the adipose tissue.

To study the impact of TCC, two $8 \mu \mathrm{m}$ sections were cut from 15 clinical breast cancer cases with
TCC ranging from 20 to $39 \%(n=7), 40-59 \%(n=$ $5)$ and $60-79 \%(n=3)$. Like in the experiments on adipose tissue contamination, effects of DCIS on assay results were minimized by selecting only samples with less than 10\% DCIS content (9 samples: 0\% DCIS; 6 samples: $\leq 10 \%$ DCIS). Sections were mounted on polyethylene naphthalate (PEN) membrane slides, stained with Cresyl violet and enriched up to almost $100 \%$ by laser microdissection with a Leica LMD DFC $7000 \mathrm{~T}$ (Leica Microsystems) or macrodissection (Fig. 1, middle panel). Sections were then transferred into RNase-free test tubes for subsequent RNA isolation and gene expression studies.

The effect of DCIS on the MammaTyper ${ }^{\circ}$ results was assessed on 24 FFPE breast cancer samples with DCIS-covered areas ranging from 10 to $60 \%$. The DCIS content was morphologically distinguished from invasive carcinoma via the preservation of the myoepithelial-cell layer, visible by standard $\mathrm{H} \& \mathrm{E}$ staining [25]. From each FFPE sample, three $8 \mu \mathrm{m}$ sections were prepared for laser microdissection. Circled areas of DCIS from two slides were quantitatively microdissected and combined into an RNase-free tube for RNA isolation. Tissue sections without the microdissected DCIS were transferred in duplicates into RNase-free tubes (Fig. 1, lower panel). Relative expression of the four genes $E R B B 2$, ESR1, PGR and MKI67 were compared between whole sections, whole sections lacking DCIS and microdissected DCIS. Moreover, $3 \mu \mathrm{m}$ sctions of these same breast cancer samples were immunostained with an anti-Her2/neu antibody (Clone EP3 Epitomics (Quartett, Berlin, Germany, using DAB as

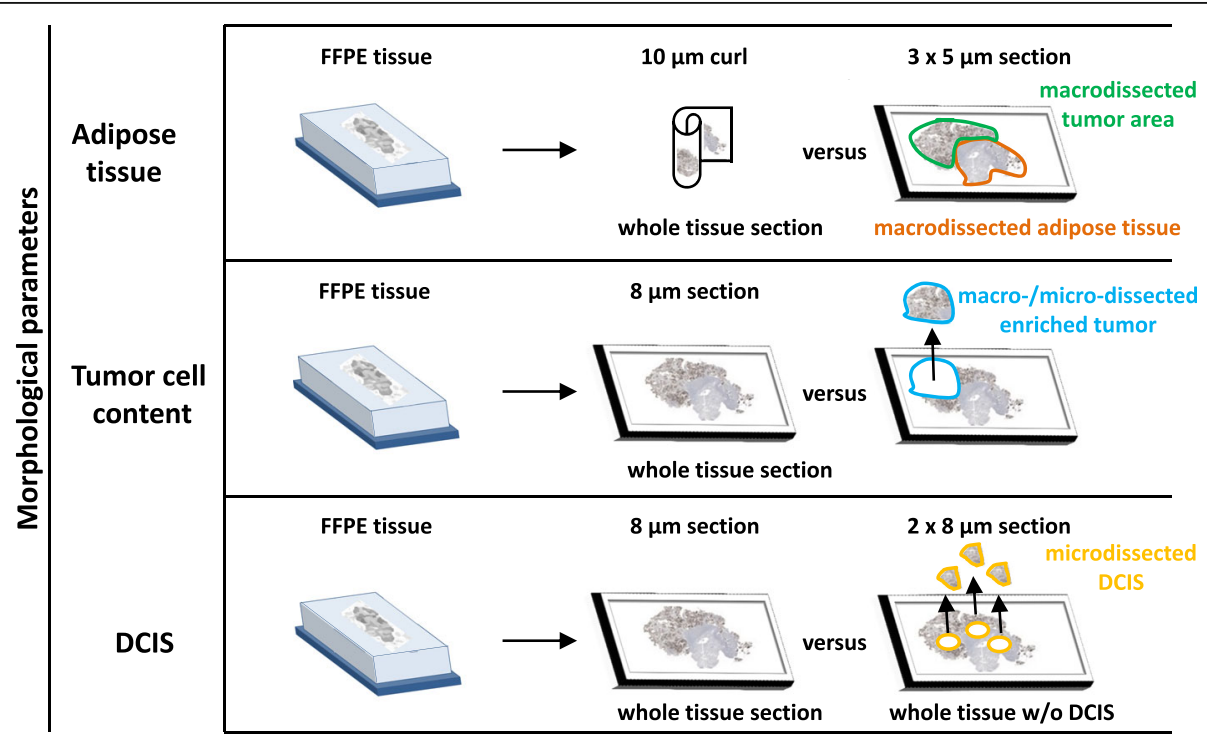

Fig. 1 Schematic overview of sample processing and morphological parameters of investigated tissue 
detection medium) in order to assess the Her2 status in invasive tumor and DCIS.

\section{$R N A$ isolation and mRNA quantification via $R T-q P C R$}

Extraction of total RNA from FFPE samples was performed using a CE-marked paramagnetic bead-based method (RNXtract ${ }^{\circ}$, BioNTech Diagnostics, Mainz, Germany) according to the manufacturers' instructions. RNA was eluted in $100 \mu \mathrm{l}, 60 \mu \mathrm{l}$ or $50 \mu \mathrm{l}$ depending on the amount of input material. The median gene expression levels of both reference genes measured within the MammaTyper ${ }^{\ominus}$ test were used as a quality measure for determining the adequacy of the amount of RNA present in the sample.

The expression levels of ERBB2, ESR1, PGR and MKI67 were determined by reverse transcription-quantitative real-time PCR (RT-qPCR) using the CE-marked MammaTyper IVD kit (BioNTech Diagnostics, Mainz, Germany) on the LightCycler 480 II qPCR platform (Roche Diagnostics) according to the manufacturer's instructions (16030190020-EN Rev. 3.1). Calculations were carried out as described previously [14]. MammaTyper results are expressed as 40 -ddCq values for each marker which represent the gene expression level in the sample relative to the amount of RNA starting material as determined by the reference genes beta-2-microglobulin (B2M) and calmodulin 2 (CALM2). In addition, each individual marker was scored positive or negative according to clinically validated marker specific cutoffs [20-22]. The following cut-offs were used: ERBB2 41.10, ESR1 38.00, PGR 35.50, MKI67 35.90.

\section{Results}

\section{Effect of adipose tissue on gene expression studies}

Due to the high ratio of cytoplasm over nuclei in adipose tissue, and therefore low cellularity, the differences of $40-\mathrm{ddCq}$ values across the tested pairs of whole sections and samples obtained after removing the surrounding adipose tissue were low. The mean absolute difference (and $\mathrm{min} / \mathrm{max}$ observed value) was 0.28 cycles for ERBB2 (0.00-0.64), 0.31 for ESR1 (0.05-0.70), 0.32 for PGR (0.02-0.94), and 0.29 for MKI67 (0.09-0.59) (Fig. 2, Additional file 1). On average, the difference was even smaller than the typical intra-run variation of 0.5 cycles observed in qPCR experiments (corresponding to a standard deviation (SD) of 0.35 cycles) [26]. The expected SD of $\mathrm{Cq}$ values is even higher ( 0.4 cycles) in the region of the limit of detection (LOD) of a qPCR [27]. The concordance of the binary categories was $100 \%$ for ERBB2, ESR 1 and PGR and $90 \%$ for MKI67 caused by one single case where the initial value was very close to the cut-off (Additional file 1, sample 3). The highest difference $(0.94$ cycles) was detected in a single case with $P G R$ gene expression close to the limit of detection in the dissected (tumor-enriched) sample (Additional file 1, sample 10).
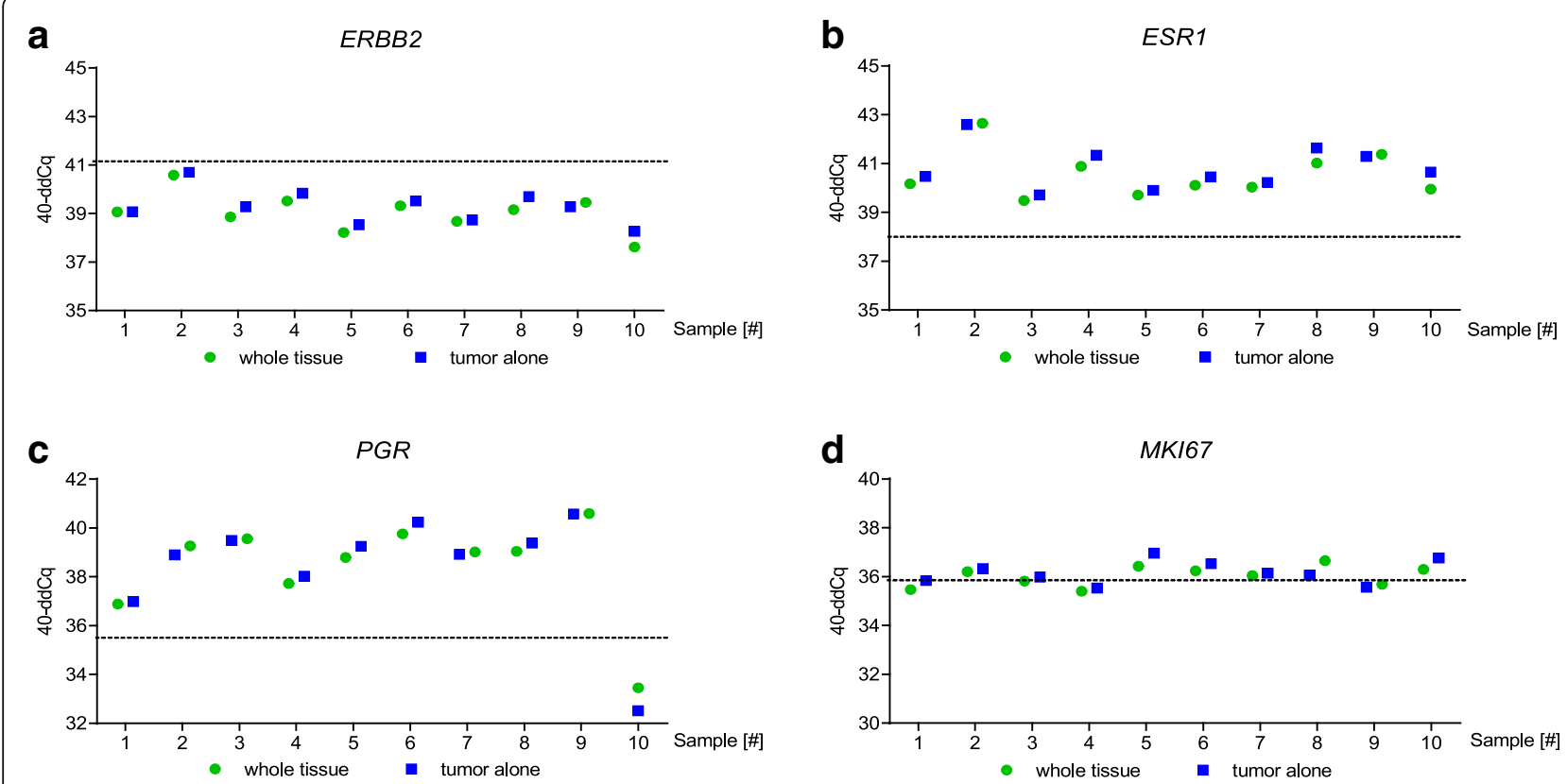

Fig. 2 Effect of adipose tissue on relative gene expression. Shown in the graph are gene expression data of $n=10$ breast cancer specimen for ERBB2(a), ESR1 (b), PGR (c) and MKI67 (d) in whole sections (over 50\% adipose tissue content, green circles) versus tumor-enriched sections (blue squares). Dotted lines represent the respective cut-off for the four marker genes (ERBB2: 41.10; ESR1: 38.00; PGR: 35.50; MKI67: 35.90) 
Table 1 Differences in MammaTyper ${ }^{\circledR}$ relative gene expression between pairs of whole tissue and tumor-enriched specimens

\begin{tabular}{|c|c|c|c|c|}
\hline \multirow{2}{*}{$\begin{array}{l}\text { Tumor } \\
\text { cell } \\
\text { content }\end{array}$} & \multicolumn{4}{|c|}{ Mean (min, max) absolute difference of 40-ddCq of paired measurements } \\
\hline & ERBB2 & ESR1 & $P G R$ & MKI67 \\
\hline $20-39 \%$ & 0.49 (0.04 to 0.86$)$ & 0.34 (0.01 to 0.80$)$ & 0.39 (0.15 to 0.72$)$ & $0.58(0.17$ to 1.46$)$ \\
\hline $40-59 \%$ & 0.38 (0.11 to 0.65$)$ & 0.53 (0.08 to 1.15$)$ & 0.49 (0.28 to 0.68$)$ & 0.58 (0.33 to 1.28$)$ \\
\hline $60-79 \%$ & 0.24 (0.15 to 0.30$)$ & 0.40 (0.22 to 0.50$)$ & 0.16 (0.04 to 0.23$)$ & 0.09 (0.01 to 0.23$)$ \\
\hline
\end{tabular}

Four out of 10 macrodissected adipose-enriched tissue samples had invalid MammaTyper results, because the RNA yield was poor, as evidenced by the very low expression levels of the reference genes. In the remaining 6 samples, the results were valid but borderline, with reference $\mathrm{Cq}$ values close to the limit of detection. The signal of the reference genes in the pooled adipose tissue was detected on average 4 cycles later than the signal from the invasive tumor area. Regarding the marker genes, the mean raw $\mathrm{Cq}$ values in the adipose tissue pools were delayed by 6 to 7 cycles compared with the tumor-enriched tissue, corresponding to a $2^{-6}$ to $2^{-7}$ change adding a linear fold change of 1.0156 or 1.0078 , respectively. This results in a negligible $\mathrm{Cq}$ change of 0.011 to -0.022 (Additional file 2).

\section{Effect of tumor cell content on gene expression studies}

The mean absolute difference in relative gene expression between samples before and after enrichment for invasive tumor was low (<0.59 Cq) (Table 1 and Fig. 3). In 7 out of 60 measurements $(11.7 \%)$ the single marker results showed an absolute difference which was higher than $0.70 \mathrm{Cq}$, the typical intra-run variation $(2 \mathrm{x} \mathrm{SD}$ of 0.35 cycles) observed in experiments with qPCR [26]. These deviations were particularly observed in 4 very small samples with a tumor area less than or equal to $25 \mathrm{~mm}^{2}$ (Additional file 3) and showed raw Cq values close to the LOD for some markers.

The binary categories were discordant in 3 MKI67 cases, having $40-\mathrm{ddCq}$ values adjacent to the cut-off (Additional file 3, sample 5, 8 and 9). As a consequence,

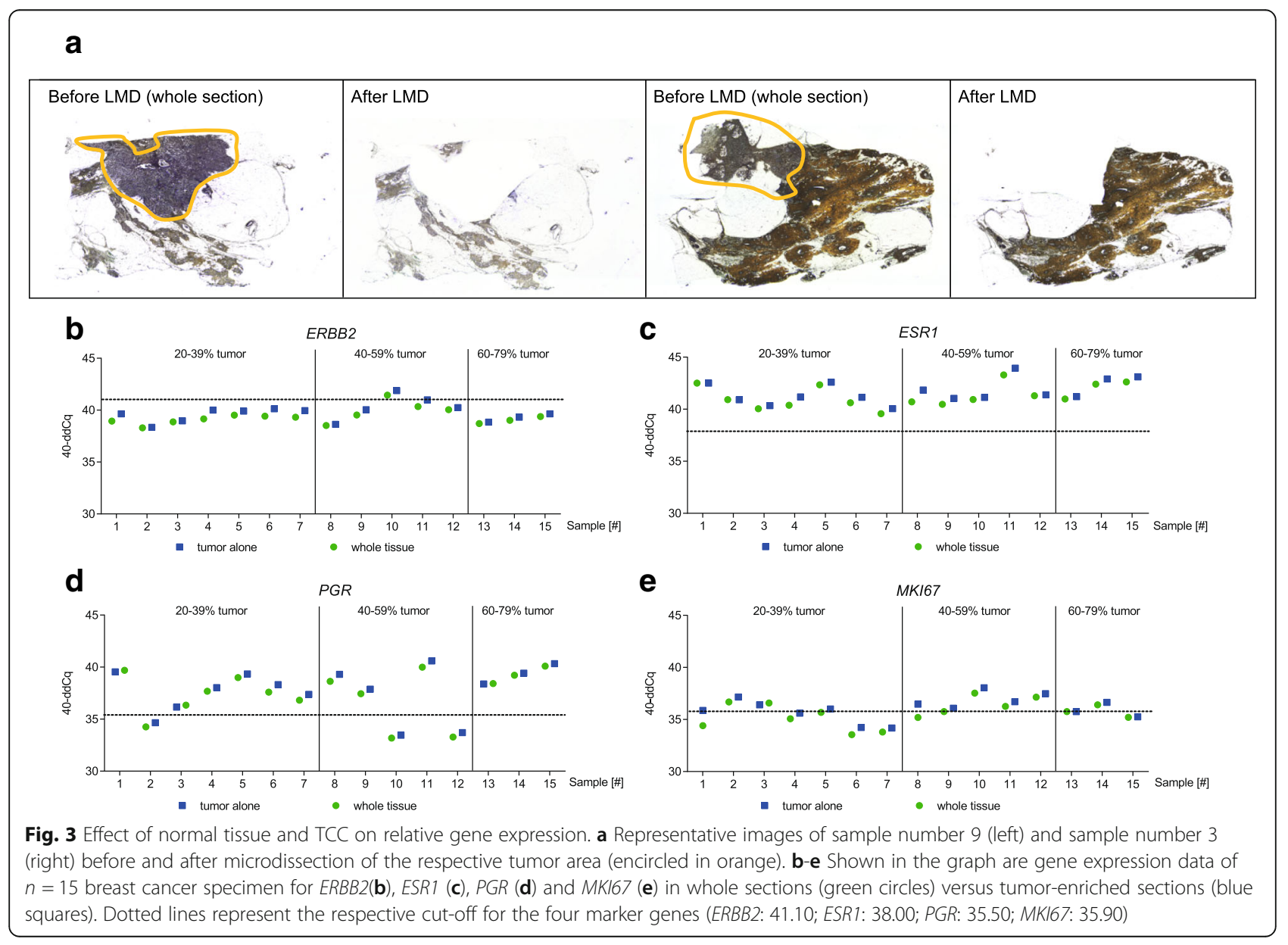


Table 2 Characteristics of tissue samples used for the analysis of DCIS on relative gene expression

\begin{tabular}{|c|c|c|c|c|}
\hline \multirow{2}{*}{$\begin{array}{l}\text { Sample } \\
\text { \# }\end{array}$} & \multirow{2}{*}{$\begin{array}{l}\text { Tumor } \\
\text { cell } \\
\text { content } \\
{[\%]}\end{array}$} & \multirow{2}{*}{$\begin{array}{l}\text { DCIS } \\
\text { content } \\
{[\%]}\end{array}$} & \multicolumn{2}{|c|}{ HER2 status (IHC) } \\
\hline & & & invasive tumor & DCIS \\
\hline 1 & $40-59$ & $10-19$ & $3+$ & $3+$ \\
\hline 2 & $60-79$ & & $3+$ & $3+$ \\
\hline 3 & 80-100 & & $3+$ & $3+$ \\
\hline 4 & 80-100 & & n.a. & n.a. \\
\hline 5 & $20-39$ & & $2+$ & $2+$ \\
\hline 6 & $60-79$ & & $2+$ & $3+$ \\
\hline 7 & $60-79$ & $20-29$ & 0 & 0 \\
\hline 8 & $60-79$ & & 0 & 0 \\
\hline 9 & $40-59$ & & 0 & $1+$ \\
\hline 10 & $40-59$ & & 0 & 0 \\
\hline 11 & 20-39 & & $1+$ & $1+$ \\
\hline 12 & $40-59$ & & $1+$ & $1+$ \\
\hline 13 & $40-59$ & & $1+$ & $2+$ \\
\hline 14 & $40-59$ & & 0 & 0 \\
\hline 15 & $60-79$ & & n.a. & n.a. \\
\hline 16 & $60-79$ & & $1+$ & $1+$ \\
\hline 17 & 20-39 & $30-39$ & 0 & $1+$ \\
\hline 18 & 20-39 & & $2+$ & $3+$ \\
\hline 19 & 20-39 & & 0 & 0 \\
\hline 20 & 20-39 & & $1+$ & $2+$ \\
\hline 21 & $40-59$ & $40-49$ & $1+$ & $1+$ \\
\hline 22 & 20-39 & $50-60$ & $1+$ & $2+$ \\
\hline 23 & 20-39 & & $1+$ & $2+$ \\
\hline 24 & $40-59$ & & $1+$ & $1+$ \\
\hline
\end{tabular}

Different scores of HER2 protein expression in DCIS and corresponding invasive tumor are shown in bold

3 Luminal A-like samples, one with 20-39\% TCC and 2 with a TCC of $40-59 \%$ were re-classified as Luminal B-like (HER2-negative) after tumor enrichment. The pairs of dissected and non-dissected samples for the other markers showed a concordance rate of $100 \%$.

\section{Effect of variable extent of DCIS on gene expression studies}

Sample characteristics used for this gene expression study are summarized in Table 2 .

40-ddCq differences across the tested pairs of whole tissue and microdissected tumor samples without DCIS were low for all four genes (Fig. 4). The mean absolute difference was $0.16 \mathrm{Cq}$ for $E R B B 2(0.00$ to $0.79 \mathrm{Cq}), 0.25$ for ESR1 (0.00 to $0.61 \mathrm{Cq}), 0.18$ for PGR (0.01 to 0.80 ) and 0.24 for $M K I 67$ (0.03 to $0.63 \mathrm{Cq}$ ) (Additional file 4). When DCIS-only samples were separately analyzed, expression profiles tended to be higher (compared to invasive tumor), exceeding the generally accepted intra-run variation of 0.70 cycles in $18 / 22$ cases for ERBB2 (81.8\%), in 19/22 cases for ESR1 (86.4\%), in 14/ 22 cases for PGR (63.6\%) and in $11 / 22$ cases for MKI67 (50.0\%). In four cases (Table 2, samples 6, 9, 17 and 18), HER2 protein expression by immunohistochemistry showed a similar trend towards higher scores in DCIS as the one observed for gene expression studies (Fig. 4b and Table 2). This trend can be especially seen in cases that turn from $2+$ (invasive tumor) to $3+$ (DCIS) and from 0 (invasive tumor) to $1+$ (DCIS). In 2 of 24 DCIS-only samples, gene expression studies were invalid due to insufficient RNA yield.

\section{Discussion}

The gene expression profiles of prognostic and predictive biomarkers in breast cancer likely differ between invasive carcinoma, non-invasive carcinoma (e.g. DCIS), non-neoplastic ductulo-lobular units, and adjacent or intervening stroma. Whole FFPE sections of breast cancinomas contain variable amounts of such tissue "contaminants". In this study, we investigated the robustness of MammaTyper ${ }^{\odot}$ an RT-qPCR-based gene-expression assay for ERBB2, ESR1, PGR and MKI67 against heterogeneity due to various tissue types. We first focused on the surrounding adipose tissue, which can easily be removed by macrodissection. By measuring the expression of reference genes we showed that the total RNA obtained from adipose tissue was on average more than 10-fold lower (3.5 Cqs) than the RNA isolated from equal volumes of invasive tumor tissue, frequently falling below the limit of detection. Even when adipose tissue occupied more than $50 \%$ of the slide area, deviations of gene expression between whole sections and sections lacking the surrounding tissue fell in the range of intra-run variance.

The observation that adipose tissue contains far less RNA than similarly sized tumor tissue is explained by the fact that adipocytes have very small nucleocytoplasmic ratios (small nuclei, voluminous cytoplasm) [28]. By contrast, cancer cells tend to exhibit a particularly high nucleocytoplasmic ratio due to their increased DNA content and reduced specialized cytoplasmic organelles. Hence, invasive tumor areas have significantly more nuclei per $\mathrm{mm}^{2}$ than surrounding non-malignant breast tissue and thus considerably larger amounts of nucleic acids. Our experiments indicate that this phenomenon is so pronounced as to trivialize the impact of RNA derived from adipose tissue on the total RNA yield of the non-dissected whole sections. The fact that RNA yields from normal breast tissue which consists largely of adipose and paucicellular fibrous tissue are often insufficient is well known and poses a challenge for studies requiring adequate non-neoplastic control material $[4,29]$. 


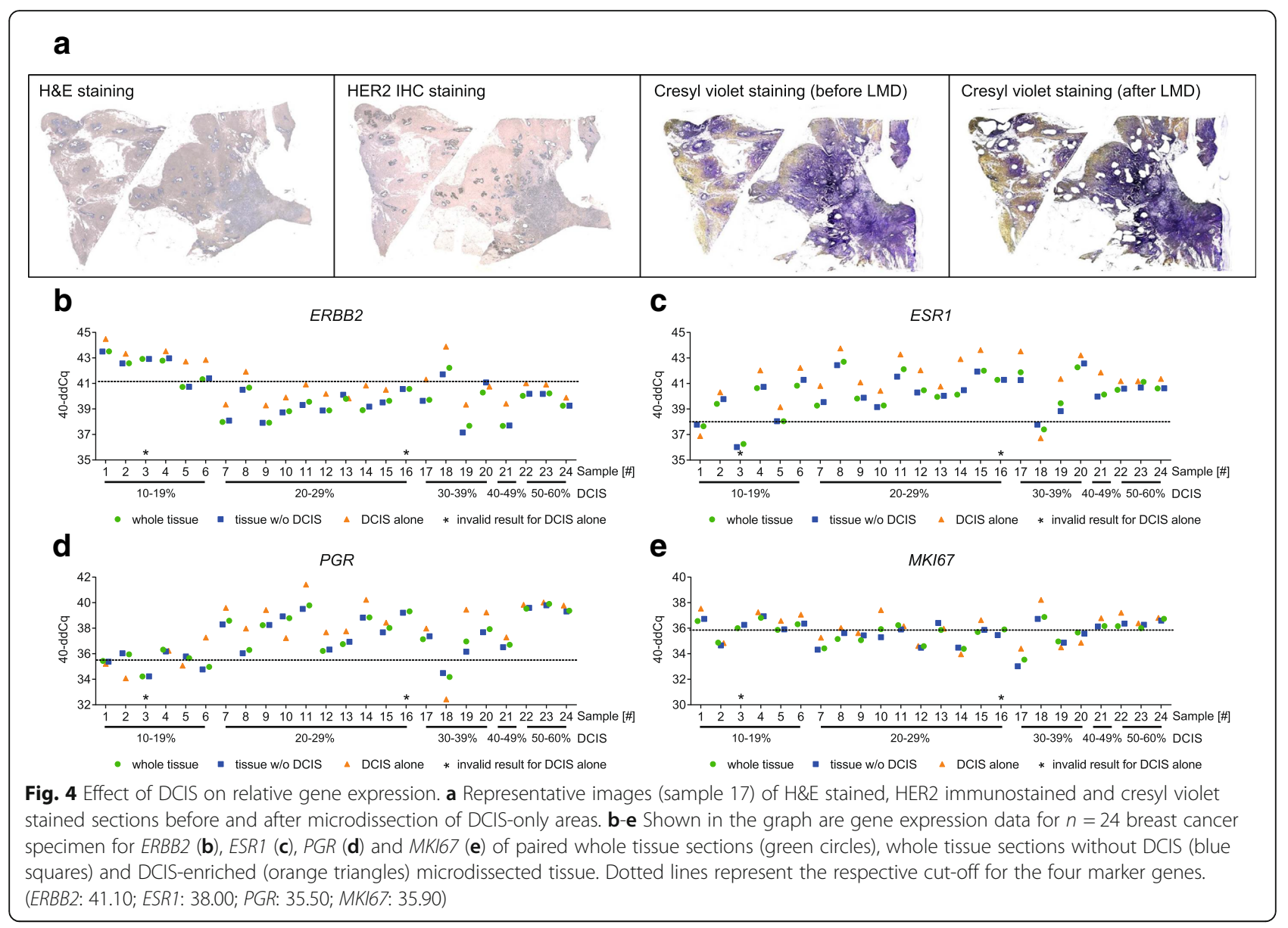

Due to the negligible influence of adipose tissue on gene expression for ERBB2, ESR1, PGR and MKI67, this component was disregarded for the calculations of the TCC. In the respective experiments, we found that changes in the relative gene expression were insignificant down to $20-39 \%$ TCC. This is in agreement with data reported by Tramm and coworkers, who showed an excellent agreement between gene expression data for ESR1, PGR and ERBB2 from whole tissue and from macrodissected extracts [30]. Likewise, macrodissection did not affect the prognostic significance of RNA expression of cancer-associated genes in primary breast tumor samples [12]. Moreover, Viale and coworkers showed that discordances between RNA microarray readouts and IHC/FISH for ER, PGR and HER2 in the MINDACT trial could not be explained by intratumoral heterogeneity or the presence of either DCIS or normal tissue [31]. In line with that, other breast cancer assays, like the GeneXpert Breast Cancer STRAT4 assay from Cepheid, that also measures the expression levels of ERBB2, ESR1, $P G R$ and MKI67, found that macrodissection of whole tissue sections is not required for accurate assessment of these genes by RT-qPCR [32].

Contrary to the findings from studies looking at the effect of TCC on the expression of individual genes,
Elloumi and coworkers found that multi-gene genomic scores were susceptible to contamination of RNA eluates by normal breast tissue [33]. However, specimen volume was not normalized, which may explain why the impact of non-tumor tissue on the expression levels of the genes of interest may have been overestimated in their study. Along the same line of reasoning, first results for the Prosigna ${ }^{\circ}$ gene signature were unstable if samples contained more than $60-70 \%$ surrounding non-tumor tissue [34]. The question whether multigene risk predictors are sensitive or not to variations of TCC is hence related to factors like test design and gene-specific ratios of tumor-vs-normal expression.

Data from studies with complex multigene predictors may not adequately address the impact of TCC on gene expression, as they depend on specificities of different genes and their particular mode of expression in different tissue compartments. For example, the outcome estimations based on $M M P 7$, a gene which encodes for an enzyme that degrades extracellular proteins, were discordant before and after macrodissection [2], most likely because RNA expression of MMP7 is higher in stroma compared to tumor cells [35]. Conversely, ERa, the clinically relevant isoform of the estrogen receptor is 
confined to epithelial cells of the breast and is not expressed in mammary fibroblasts [36]. Thus, the impact of TCC on RNA relative quantification is gene-specific and as far as MammaTyper genes ERBB2, ESR1, PGR and MKI67 are concerned the bias introduced by the inclusion of tissue surrounding the invasive tumor appears to be non-critical.

The present study underscores the fact that caution must be applied when analyzing samples that are critically small in size and hence yield only low amounts of RNA. Depending on how close the respective value lies to the limit of detection, gene expression may be affected by tumor cell enrichment.

It is well documented that gene expression patterns and molecular breast cancer subtypes may vary considerably between invasive tumor and DCIS [4, 23]. In keeping with diagnostic anatomo-pathological experience, the relative expression of ERBB2, ESR1, PGR and $M K I 67$ in our study was often higher in DCIS samples than in samples enriched for invasive carcinomas. Why DCIS is nevertheless only a weak contaminant may be explained by the reduced cellularity of DCIS vs. invasive carcinomas due to cribriform and clinging architecture as well as central necrosis. Others have previously shown that the mean RNA recovery from DCIS was substantially lower than that of invasive tumor of similar volume [1-4]. Thus, it appears that DCIS does not bias gene expression of ERBB2, ESR1, PGR and MKI67 because the contributory gene expression of DCIS is diluted.

Compared to previous work exploring the significance of TCC on the stability of gene expression assays, our present study has the advantage of addressing biological diversity of whole sections which underlies the apparent histological heterogeneity. Eventually, whether surrounding adipose tissue, normal tissue adjacent to tumor or admixed DCIS, the RT-qPCR signal is dominated by the invasive tumor component, allowing for consistent calculations in whole sections with up to $60 \%$ DCIS and in a TCC range of $20-100 \%$. This TCC range remains sufficient even if the tissue area excluding adipose tissue occupies less than $50 \%$ of the whole section, indicating that macrodissection of surrounding adipose tissue is not required. Moreover, by using archived material from actual patient cases, our data are meaningful for use in a real-life routine pathology diagnostic setting.

\section{Conclusion}

Our data indicate that MammaTyper is capable of tolerating low-purity input material with a minimum TCC of $20 \%$. Based on these thresholds, the assay can be used for the robust quantification of ERBB2, ESR1, PGR and $M K I 67$ on whole sections of FFPE samples during routine histopathological work-up of breast carcinoma.

\section{Additional files}

Additional file 1: Mammatyper ${ }^{\oplus}$ relative gene expression and $\Delta 40$-ddCq values are shown for the effect of adipose tissue. (XLSX $11 \mathrm{~kb}$ )

Additional file 2: Mammatyper ${ }^{\oplus}$ Median $\mathrm{Cq}$ values are shown for the effect of adipose tissue. (XLSX $16 \mathrm{~kb}$ )

Additional file 3: Mammatyper ${ }^{\oplus}$ relative gene expression and $\Delta 40-\mathrm{ddCq}$ values are shown for the effect of TCC. (XLSX $13 \mathrm{~kb}$ )

Additional file 4: Mammatyper ${ }^{\oplus}$ relative gene expression and $\triangle 40-d d C q$ values are shown for the effect of DCIS. Tumor cell content, DCIS content, HER2 immunohistochemical score of the invasive tumor and the DCIS, as well as relative expression of the mRNA markers ERBB2, ESR1, PGR and MKI67 and absolute $\Delta 40-\mathrm{ddCq}$ values are shown. (XLSX $16 \mathrm{~kb}$ )

\section{Abbreviations}

B2M: beta-2-microglobulin; CALM2: calmodulin 2; Cq: quantification cycle;

DCIS: ductal carcinoma in situ; ER: estrogen receptor; ERBB2: human epidermal growth factor receptor 2; ESR1: estrogen receptor 1;

FFPE: formalin-fixed paraffin-embedded; H\&E: hematoxylin and eosin; HER2: human epidermal growth factor receptor 2; IHC: immunhistochemistry; IVD: in vitro diagnostic; LMD: laser microdissection; MKI67: marker of proliferation Ki-67; mRNA: messenger RNA; PEN: polyethylene naphthalate; PGR: progesterone receptor; PR: progesterone receptor; RT-qPCR: reverse transcription-quantitative real time PCR; TCC: tumor cell content

\section{Acknowledgements}

We gratefully acknowledge Dr. Jeanette Reimann-Kreft for support with the tumor cell content evaluation and residual tissue classification of the breast cancer samples and Susanne Gebhardt (University clinic Mainz, Germany) for kind selection of tissue samples from breast cancer patients. We thank Sotirios Lakis for critical review and improvement of the manuscript. In addition, we thank Lukas Krimmer, Katharina Kaiser and Daniela Weiser (BioNTech Diagnostics GmbH, Mainz, Germany), as well as Regina Dorin (Friedrichshafen) for excellent technical assistance.

Funding

Not applicable.

Availability of data and materials

The datasets used and/or analyzed during the current study are available from the corresponding author on reasonable request.

\section{Authors' contributions}

$\mathrm{KH}$ reviewed the histomorphologic and immunohistochemical data and helped draft the manuscript. KS analyzed the MammaTyper ${ }^{\circledast}$ data and KS, $\mathrm{ML}, \mathrm{CG}$, US helped draft the manuscript. $\mathrm{KH}, \mathrm{ML}$ collected the tissue samples. MS reviewed the manuscript and provided tissue samples. HAL conceived, designed, and coordinated the study, analyzed the Her2

immunohistochemical data and helped draft the manuscript. All authors read and approved the final manuscript.

\section{Ethics approval and consent to participate}

The study consisted of 49 human FFPE invasive breast carcinoma samples. Thirteen cases were derived from the Institute of Molecular Gynecological Oncology, Mainz, Germany. The use of archived samples was approved by the ethics committee of the Landesärztekammer Rheinland-Pfalz (837.139.05 (4797)). Thirty one cases were obtained from PATH Biobank (Patients' Tumour Bank of Hope), Munich, Germany [24]. Patients provided individual, written informed consent for the storage of samples and data, follow-up contact, and further use of samples and data for research purposes. The processes of PATH Biobank have been approved by the ethics committee of the medical faculty of the University of Bonn (255/06). Five additional cases were purchased from commercial vendors (Asterand Biosciences, Detroit, USA Ml; Proteogenex, Culver City, USA CA).

Consent for publication

Not applicable. 


\section{Competing interests}

US is founder and CEO of BioNTech Diagnostics GmbH. KH, KS, ML and CG are employees of BioNTech Diagnostics $\mathrm{GmbH}$. MS and HAL declare that they have no competing interests.

\section{Publisher's Note}

Springer Nature remains neutral with regard to jurisdictional claims in published maps and institutional affiliations.

\section{Author details}

${ }^{1}$ BioNTech Diagnostics GmbH, An der Goldgrube 12, 55131 Mainz, Germany. ${ }^{2}$ Department of Obstetrics and Gynecology, Johannes Gutenberg University, Langenbeckstraße 1, 55131 Mainz, Germany. ${ }^{3}$ BioNTech AG, An der Goldgrube 12, 55131 Mainz, Germany. ${ }^{4}$ Institute of Pathology, Medizin Campus Bodensee, Röntgenstraße 2, 88048 Friedrichshafen, Germany.

\section{Received: 4 September 2018 Accepted: 10 October 2018}

\section{Published online: 20 October 2018}

\section{References}

1. Finak G, Bertos N, Pepin F, Sadekova S, Souleimanova M, Zhao H, et al. Stromal gene expression predicts clinical outcome in breast cancer. Nat Med. 2008;14:518-27. https://doi.org/10.1038/nm1764

2. Kotoula V, Kalogeras KT, Kouvatseas G, Televantou D, Kronenwett R, Wirtz $\mathrm{RM}$, et al. Sample parameters affecting the clinical relevance of RNA biomarkers in translational breast cancer research. Virchows Arch. 2012:462: 141-54. https://doi.org/10.1007/s00428-012-1357-1

3. Ma X-J, Dahiya S, Richardson E, Erlander M, Sgroi DC. Gene expression profiling of the tumor microenvironment during breast cancer progression. Breast Cancer Res. 2009;11. https://doi.org/10.1186/bcr2222

4. Schobesberger M, Baltzer A, Oberli A, Kappeler A, Gugger M, Burger H, et al. Gene expression variation between distinct areas of breast cancer measured from paraffin-embedded tissue cores. BMC Cancer. 2008;8. https://doi.org/ 10.1186/1471-2407-8-343

5. Hagemann IS. Molecular testing in breast Cancer: a guide to current practices. Arch Pathol Lab Med. 2016;140:815-24. https://doi.org/10.5858/ arpa.2016-0051-RA.

6. Hammond ME, Hayes DF, Dowsett M, Allred DC, Hagerty KL, Badve S, et al American Society of Clinical Oncology/College of American Pathologists guideline recommendations for immunohistochemical testing of estrogen and progesterone receptors in breast cancer. Arch Pathol Lab Med. 2010; 134:907-22. https://doi.org/10.1043/1543-2165-134.6.907

7. Polley MY, Leung SC, MCShane LM, Gao D, Hugh JC, Mastropasqua MG, et al. An international Ki67 reproducibility study. J Natl Cancer Inst. 2013;105: 1897-906. https://doi.org/10.1093/jnci/djt306

8. Rakha EA, Pinder SE, Bartlett JM, Ibrahim M, Starczynski J, Carder PJ, et al. Updated UK recommendations for HER2 assessment in breast cancer. J Clin Pathol. 2015;68:93-9. https://doi.org/10.1136/jclinpath-2014-202571 .

9. Varga Z, Diebold J, Dommann-Scherrer C, Frick H, Kaup D, Noske A, et al. How reliable is Ki-67 immunohistochemistry in grade 2 breast carcinomas? A QA study of the Swiss working Group of Breast- and Gynecopathologists. PLoS One. 2012;7:e37379. https://doi.org/10.1371/journal.pone.0037379 .

10. Graham K, Ge X, de las Morenas A, Tripathi A, Rosenberg CL. Gene expression profiles of estrogen receptor-positive and estrogen receptornegative breast cancers are detectable in histologically Normal breast epithelium. Clin Cancer Res. 2010;17:236-46. https://doi.org/10.1158/10780432.ccr-10-1369

11. Ma XJ, Salunga R, Tuggle JT, Gaudet J, Enright E, McQuary P, et al. Gene expression profiles of human breast cancer progression. Proc Natl Acad Sci. 2003;100:5974-9. https://doi.org/10.1073/pnas.0931261100

12. Poremba C, Uhlendorff J, Pfitzner BM, Hennig G, Bohmann K, Bojar H, et al. Preanalytical variables and performance of diagnostic RNA-based gene expression analysis in breast cancer. Virchows Arch. 2014;465:409-17. https://doi.org/10.1007/s00428-014-1652-0

13. Goldhirsch A, Winer EP, Coates AS, Gelber RD, Piccart-Gebhart M, Thurlimann B, et al. Personalizing the treatment of women with early breast cancer: highlights of the St Gallen international expert consensus on the primary therapy of early breast Cancer 2013. Ann Oncol. 2013;24:2206-23. https://doi.org/10.1093/annonc/mdt303

14. Laible M, Schlombs K Kaiser K, Veltrup E, Herlein S, Lakis S, et al. Technical validation of an RT-qPCR in vitro diagnostic test system for the determination of breast cancer molecular subtypes by quantification of ERBB2, ESR1, PGR and MKI67 mRNA levels from formalin-fixed paraffinembedded breast tumor specimens. BMC Cancer. 2016;16. https://doi.org/ 10.1186/s12885-016-2476-X

15. Schwanhäusser B, Busse D, Li N, Dittmar G, Schuchhardt J, Wolf J, et al. Global quantification of mammalian gene expression control. Nature. 2011; 473:337-42. https://doi.org/10.1038/nature10098

16. Fountzilas G, Christodoulou C, Bobos M, Kotoula V, Eleftheraki AG, Xanthakis I, et al. Topoisomerase II alpha gene amplification is a favorable prognostic factor in patients with HER2-positive metastatic breast cancer treated with trastuzumab. J Transl Med. 2012:10:212. https://doi.org/10.1186/1479-5876-10-212.

17. Schleifman EB, Desai R, Spoerke JM, Xiao Y, Wong C, Abbas I, et al. Targeted biomarker profiling of matched primary and metastatic estrogen receptor positive breast cancers. PLoS One. 2014;9:e88401. https://doi.org/10.1371/ journal.pone.0088401

18. Wilson TR, Xiao Y, Spoerke JM, Fridlyand J, Koeppen H, Fuentes E, et al. Development of a robust RNA-based classifier to accurately determine ER, $\mathrm{PR}$, and HER2 status in breast cancer clinical samples. Breast Cancer Res Treat. 2014:148:315-25. https://doi.org/10.1007/s10549-014-3163-8 .

19. Duffy MJ, Harbeck N, Nap M, Molina R, Nicolini A, Senkus E, et al. Clinical use of biomarkers in breast cancer: updated guidelines from the European group on tumor markers (EGTM). Eur J Cancer. 2017;75:284-98. https://doi. org/10.1016/j.ejca.2017.01.017

20. Sinn H-P, Schneeweiss A, Keller M, Schlombs K, Laible M, Seitz J, et al. Comparison of immunohistochemistry with PCR for assessment of ER, PR, and $\mathrm{Ki}-67$ and prediction of pathological complete response in breast cancer. BMC Cancer. 2017;17. https://doi.org/10.1186/s12885-017-3111-1

21. Varga Z, Lebeau A, Bu H, Hartmann A, Penault-Llorca F, Guerini-Rocco E, et al. An international reproducibility study validating quantitative determination of ERBB2, ESR1, PGR, and MKI67 mRNA in breast cancer using MammaTyper ${ }^{\circledast}$. Breast Cancer Res. 2017;19. https://doi.org/10.1186/s13058017-0848-z

22. Wirtz RM, Sihto H, Isola J, Heikkilä P, Kellokumpu-Lehtinen P-L, Auvinen P, et al. Biological subtyping of early breast cancer: a study comparing RT-qPCR with immunohistochemistry. Breast Cancer Res Treat. 2016;157:437-46. https://doi.org/10.1007/s10549-016-3835-7.

23. Tamimi RM, Baer HJ, Marotti J, Galan M, Galaburda L, Fu Y, et al. Comparison of molecular phenotypes of ductal carcinoma in situand invasive breast cancer. Breast Cancer Res. 2008;10. https://doi.org/10.1186/ bcr2128.

24. Waldmann A, Anzeneder T, Katalinic A. Patients and methods of the PATH biobank - a resource for breast Cancer research. Geburtshilfe Frauenheilkd. 2014:74:361-9. https://doi.org/10.1055/s-0033-1360263

25. Pandey PR. Role of myoepithelial cells in breast tumor progression. Front Biosci. 2010;15:226. https://doi.org/10.2741/3617

26. Kennedy S, Oswald N. PCR troubleshooting and optimization : the essential guide. Norfolk, UK: Caister Academic Press; 2011. vii, 235 p., 4 p. of plates p.

27. Stahlberg A, Kubista M. The workflow of single-cell expression profiling using quantitative real-time PCR. Expert Rev Mol Diagn. 2014;14:323-31. https://doi.org/10.1586/14737159.2014.901154

28. LCUa J, Carneiro J. Basic histology. 11th ed. New York, USA: McGraw Hill; 2005. p. 123-7.

29. Mee BC, Carroll P, Donatello S, Connolly E, Griffin M, Dunne B, et al. Maintaining breast Cancer specimen integrity and individual or simultaneous extraction of quality DNA, RNA, and proteins from Allprotectstabilized and nonstabilized tissue samples. Biopreservation and Biobanking. 2011;9:389-98. https://doi.org/10.1089/bio.2011.0034

30. Tramm T, Hennig G, Kyndi M, Alsner J, Sørensen FB, Myhre S, et al. Reliable $P C R$ quantitation of estrogen, progesterone and ERBB2 receptor mRNA from formalin-fixed, paraffin-embedded tissue is independent of prior macrodissection. Virchows Arch. 2013;463:775-86. https://doi.org/10.1007/s00428013-1486-1.

31. Viale G, Slaets L, De Snoo F, van 't Veer LJ, Rutgers EJ, Bogaerts J, et al. Comparison of molecular (BluePrint and MammaPrint) and pathological subtypes for breast cancer among the first 800 patients from the EORTC 10041/BIG 3-04 (MINDACT) trial. J Clin Oncol. 2012;30:32. https://doi.org/10. 1200/jco.2012.30.27_suppl.32

32. Elloumi F, Hu Z, Li Y, Parker JS, Gulley ML, Amos KD, et al. Systematic Bias in genomic classification due to contaminating non-neoplastic tissue in breast tumor samples. BMC Med Genet. 2011;4. https://doi.org/ $10.1186 / 1755-8794-4-54$ 
33. Gupta S, Mani NR, Carvajal-Hausdorf DE, Bossuyt V, Ho K, Weidler J, et al. Macrodissection prior to closed system RT-qPCR is not necessary for estrogen receptor and HER2 concordance with IHC/FISH in breast cancer. Lab Investig. 2018. https://doi.org/10.1038/s41374-018-0064-1.

34. Nielsen T, Wallden B, Schaper C, Ferree S, Liu S, Gao D, et al. Analytical validation of the PAM50-based Prosigna breast Cancer prognostic gene signature assay and nCounter analysis system using formalin-fixed paraffinembedded breast tumor specimens. BMC Cancer. 2014;14. https://doi.org/ 10.1186/1471-2407-14-177

35. Kohrmann A, Kammerer U, Kapp M, Dietl J, Anacker J. Expression of matrix metalloproteinases (MMPs) in primary human breast cancer and breast cancer cell lines: new findings and review of the literature. BMC Cancer. 2009:9:188. https://doi.org/10.1186/1471-2407-9-188

36. Palmieri C, Saji S, Sakaguchi H, Cheng G, Sunters A, O'Hare MJ, et al. The expression of oestrogen receptor (ER)-beta and its variants, but not ERalpha, in adult human mammary fibroblasts. J Mol Endocrinol. 2004;33:35-50 https://www.ncbi.nlm.nih.gov/pubmed/15291741.

Ready to submit your research? Choose BMC and benefit from:

- fast, convenient online submission

- thorough peer review by experienced researchers in your field

- rapid publication on acceptance

- support for research data, including large and complex data types

- gold Open Access which fosters wider collaboration and increased citations

- maximum visibility for your research: over $100 \mathrm{M}$ website views per year

At BMC, research is always in progress.

Learn more biomedcentral.com/submissions 